\title{
Study on the Performance and Control of the Folk Custom-Sparkler- Grabbing of Dong Nationality under Festival Tourism Perspective
}

\author{
Changgan Fang1, a
}

1 School of Economic and Commerce .South China University of Technology,Guangdong, China

a ff2986@163.com

Keywords: Sparkler-Grabbing; Festival Tourism; Dong Nationality

\begin{abstract}
It is conducive to the formation of national unity for the control on its collective entertainment, watching, competitiveness of the performance of Sparkler-Grabbing in Festival Tourism, while the competitive and antagonistic characteristics are conducive to cultivating the national combatant spirit.
\end{abstract}

\section{Introduction}

Performance of Sparkler-Grabbing. The traditional Sparkler-Grabbing Sport widely spread in Dong Nationality Areas has unique national style. Every year On the3rd of the3rd lunar month, or after the autumn harvest, the sparkler-grabbing sport will be held in Dong Nationality areas. Men and women, the old and the young, will wear traditional costumes to watch the sports game at the place the game is held. Competitors sent from all villages are required to be strong in body and fast in speed. Before the game, the host will make preparation for the sparkler.Sparkler is a kind of circle made of ivy or green fine bamboo, a total of 3 cup-size circles, the circles are wrapped around by red cloth representing happiness meaning, and fixed by red and green lines. After the host declaring starting, the cone cylinder of height of about $15 \mathrm{~cm}$ is fired with gunpowder, then the circle is pushed shot to the sky, players sent by villages start grabbing, player grasping the circle is not the winner, who still needs to protect it and bring it to the destination in the process of competing with others, to win the final victory. At this time, bells and drums sound simultaneously, and fire a gun for 3 times to the congratulations of the birth of "first sparkler". The location for the next sparkler-grabbing sport game will be held in the place where the one who gets the "first sparkler"lives. After racing for the "first sparkler", the second and the third sparklers will be raced with the same rule with much bigger activities. After the forth and the fifth sparklers, the host will announce that the sparkler-grabbing sport comes to an end. The winners can receive the worship prize such as pig,goat and wine. This activity cannot do without the flowers. The tables used for placing worships and the mirror screens are decorated with flowers, and worships such as pigs and goats are also decorated with flowers, for a reflection of the titles for sparkler-grabbing winners.Sanjiang County, located in the northern part of Guangxi, is the Dong Autonomous Region, Fulu, Guyi, Linxi, Meilin and Chengyang are the villages and towns with the prevalence of Sparkler-Grabbing, but, the schedule of holding this event in each region is different (table 1).

Table 1, the schedule of Sparkler-Grabbing in Guangxi Dong Autonomous Region

\begin{tabular}{|c|c|}
\hline Region & \multicolumn{1}{|c|}{ Schedule } \\
\hline Fulu & On the 3rd of the 3rd lunar month \\
\hline Linxi & On the 26 of the $10^{\text {th }}$ lunar month \\
\hline Meilin & On the $2^{\text {nd }}$ of the $2^{\text {nd }}$ lunar month \\
\hline Chengyang & On the 3rd of the 1 st lunar month \\
\hline
\end{tabular}

\section{Changing from old rules to new rules}

2.1 Old rules. For the origin of the Sparkler-Grabbing of the Dong nationality, the earliest record is that Guangdong commercial dock workers participating in the competition for the sparkler circle 
in the air. According to Sanjiang county annals, during the years of Jiajing in Ming Dynasty, people from Fujian, Guangdong came to Geliang village (the cradle of Sparkler-Grabbing) for business, part of the settled down here. In order to purchase more cheap native products, they tried every means to attract the villagers living in the mountains, the Sparkler-Grabbing was one of the sports activities they used. Villagers of Geliang had heavy superstitious beliefs, merchants adopted Godtournament and other festivals to hold Sparkler-Grabbing activity, then the villagers on the mountain came down. Businessmen from Fujian introduced the folk culture of "Goddess of the sea" of Fujian into Geliang village, then later, people decorated "Goddess of the sea" with flowers. Decoration with flowers further developed into the Sparkler-Grabbing activity with battle atmosphere, action thriller, leaving a deep impression on the audience.

2.2New rules. After many years of practice and reform, great changes happened in both the circle and competition rules of the Sparkler-Grabbing. First, the circle is changed into oblateness made of rubber from the traditional iron hoop, this prevents the contestants from hurting when they compete for the sparkler, and the length of the sparkler is also changed from the original $5 \mathrm{~cm}$ to 15 $\mathrm{cm}$. The venue also has a new standard, the site is a rectangular grass or land, the required length of 60 meters, width of 50 meters, and line width of $12 \mathrm{~cm}$, each end of the field is set up with the sparkler platform, with a basket of flowers in each side. The new rules divide the activity into first, second half, each of 20 minutes, a whole of 40 minutes, in the half way, the participants can take a 10 minute break. The number of participants is about 5 to 8, including one captain. The SparklerGrabbing under new rules is not subject to the restrictions of "three sparklers", but stipulating the time, within the prescribed time, the player who has thrown most sparklers in the others' basket will win the game.

\section{Control features of the Folk Custom-Sparkler-Grabbing of Dong Nationality under Festival Tourism Perspective}

3.1 Collective Entertainment. It plays a role in promoting unity in the Dong area to carry out the sparkler activity among Dong people group. Prior to the game, people of each village will carry out preparations and communicate with each other, some of organizers and service providers, and some viewers, they come from all directions to participate in activity, promoting the unity of nationality, and strengthening the collective consciousness of national unity. The festival tourism is a kind of collective activity, and the Sparkler-Grabbing, as a collective sport liked by the group of the Dong people, held in the festival tourism, enriches people's cultural life. When holding the Sparkler-Grabbing in festival tourism, 8 players of two teams can participate the game. And, before the game, mobilizing the players to work together, so as to fully play their roles under the premise of mutual cooperation.

3.2 Competitiveness. The traditional sparkler-grabbing sport game is not held on the flat ground, but on the hillside or on the flat ground near the river. The number for participating is unlimited. After the sparkler are beaten out, it may be left in the valley or between the cliff, or in the river, the environment of which may better test the competitive awareness of the competitors, including the speed and skill of running, endurance and flexibility of the body and resourcefulness and courage, which are inseparable parts. Due to its strong features of competition, the sparkler-grabbing game of the Dong nationality has become a folk sports game in parallel with the modern mainstream sports.

The Sparkler-Grabbing of Dong nationality has strong stimulation and challenge, it challenges human physical strength, explosive force, sprint speed, and the flexibility, suitable for carrying out in the festival tourism. Carrying out Sparkler-Grabbing in the festival tourism, during the grabbing process, bodies squeezing, pressing, pushing and pulling can be frequently seen. This activity also has a cultured method, chasing, cuddling, stopping, robbing and other cations can be used. Such a game is full of high speed, high intensity of confrontation, and fierce struggle, which can not only improve one's health, but also cultivate people's positive sports spirit.

3.3Ornamental feature.In the festival tourism, there is no lack of activity with strong ornamental character. The tension, exciting competitive scene of the Sparkler-Grabbing of Dong 
nationality has strong ornamental character. In the course of watching, tourists can not only obtain visual enjoyment of power and beauty, but also find a brave struggle, unity and cooperation of the spirit from active action coordination of players, so as to stimulate people's positive psychology, enhance the optimistic attitude towards life. And, according to the local festival folk, the colorful "sparkler parade" can be also held (table 2).

Table 2, the colorful "sparkler parade" can be also held

\begin{tabular}{|l|l|}
\hline \multicolumn{1}{|c|}{ Type } & \multicolumn{1}{|c|}{ Specific characteristics } \\
\hline $\begin{array}{l}\text { Dragon } \\
\text { and lion } \\
\text { dance } \\
\text { team }\end{array}$ & $\begin{array}{l}\text { Starting with the salvo, opening dance by Lusheng team, girls wearing silver to } \\
\text { participate in, and followed by the Dragon Lion Dance Team. }\end{array}$ \\
\hline $\begin{array}{l}\text { Folk } \\
\text { songs }\end{array}$ & $\begin{array}{l}\text { When tourists gathering, the music playibg, Dong girls and boys who are dressed in } \\
\text { festive costumes to dance and sing folk songs to celebrate the festival. }\end{array}$ \\
\hline $\begin{array}{l}\text { Dong } \\
\text { drama } \\
\text { performan } \\
\text { ce }\end{array}$ & $\begin{array}{l}\text { Through the content adaptation and innovation performance props, performing the } \\
\text { love song program of Dong girls and boys in love. }\end{array}$ \\
\hline $\begin{array}{l}\text { Lusheng } \\
\text { playing }\end{array}$ & $\begin{array}{l}\text { Several Dong people playing Lusheng in the middle of the tourist, others gather in a } \\
\text { circle, playing Lusheng and dancing, the loud music makes tourists impressed. }\end{array}$ \\
\hline
\end{tabular}

\section{Conclusion}

Holding this traditional folk sport of Sparkler-Grabbing activity of Dong nationality in festival tourism neither has strict rules, nor normative provisions in technique, site selection is optional, with the features of locality, practicability, diversification, complexity and variability. The use of the traditional Dong Sparkler-Grabbing folk sport can both promote the development of fitness and tourism industry, and promote the continuous promotion and innovation of Sparkler-Grabbing activity of Dong nationality, which can strengthen national unity and social harmony, and play an important role for the dissemination of Chinese folk sports culture.

\section{Acknowledgments}

[This study was supported by grants from the National Natural Science Foundation of China（to DAI guangquan) (No. 41571132)

\section{References}

[1]Wang Yu. Deity Sha and Altar Sha-The Ancient Religion and Culture of the Dong People [J]. Chinese Handcraft, 2006 (02): 77-90.

[2]Peng Fenglin, Yuan Xiujun. Research on the course and the value of fitness of the SparklerGrabbing activity in Ethnic minorities in Guangxi[J]. Inner Mongolia sports science and technology, 2011 (04) : 44-46.

[3]Li Zongxi. Research on rheology and its modern development of Sparkler-Grabbing activity in Dong nationality [J]. Guangxi University For Nationalities, 2011 (01): 28-40.

[4]Liu Xianbiao, Tao Rujun. Sparkler-Grabbing festival of Dong nationality, Wonderful Oriental football event[J]. Chinese heritage, 2007 (04) : 48-49.

[5]Jiang Yong, Wang Tianyi. Study on the social value and practical significance of Zhuang nationality traditional sports-the Sparkler-Grabbing[J].Journal of Taiyuan City Vocational College, 2010 (01): 42-45.

[6]Xue Guo-you. Research on the Marketing Mode and Strategy of Small and Medium Sized Enterprises Under the E-Commerce[J] (in Chinese). Modernization of Shopping Mall. 2013 (11): 105-106. 